\title{
LCO flutter of cantilevered woven glass/epoxy laminate in subsonic flow
}

\begin{abstract}
The paper presents aeroelastic characteristics of a cantilevered composite wing, idealized as a composite flat plate laminate. The composite laminate was made from woven glass fibers with epoxy matrix. The elastic and dynamic properties of the laminate were determined experimentally for aeroelastic calculations. Aeroelastic wind tunnel testing of the laminate was performed and the result showed that flutter, a dynamic instability occurred. The cantilevered laminate also displayed limit cycle amplitude, post-flutter oscillation. The experimental flutter velocity and frequency were verified by our computational analysis.
\end{abstract}

Keyword: Limit cycle oscillation; Flutter; Laminate 